\section{Historical epidemiology and global health history}

\section{Epidemiologia histórica e história global da saúde}

James Webb Jr. ${ }^{i}$

' Professor emeritus, History Department/Colby College.
Waterville - Maine - USA
orcid.org/0000-0002-1547-1222
jlwebb@colby.edu

Received on 11 May 2019.

Approved on 27 Aug. 2019.
WEBB JR., James. Historical epidemiology and global health history. História, Ciências, Saúde - Manguinhos, Rio de Janeiro, v.27, supl., set. 2020, p.13-28.

\section{Abstract}

The subdiscipline of historical epidemiology holds the promise of creating a more robust and more nuanced foundation for global public health decision-making by deepening the empirical record from which we draw lessons about past interventions. This essay draws upon historical epidemiological research on three global public health campaigns to illustrate this promise: the Rockefeller Foundation's efforts to control hookworm disease (1909-c.1930), the World Health Organization's pilot projects for malaria eradication in tropical Africa (1950s-1960s), and the international efforts to shut down the transmission of Ebola virus disease during outbreaks in tropical Africa (1974-2019).

Keywords: public health; history; epidemiology; disease outbreaks.

\section{Resumo}

A subdisciplina epidemiologia histórica se propõe a criar um alicerce robusto e refinado para o processo de tomada de decisões em saúde pública global, aprofundando registros empíricos que nos ensinam sobre intervenções passadas. Este artigo se baseia na pesquisa epidemiológica histórica de três campanhas globais de saúde pública para ilustrar essa proposta: os esforços da Fundação Rockefeller para controle da ancilostomose (1909-c.1930), os projetospiloto da Organização Mundial da Saúde para erradicação da malária na África tropical (décadas de 1950-1960), e os esforços internacionais de interrupção da transmissão do vírus Ebola durante surtos na África tropical (1974-2019).

Palavras-chave: saúde pública; história; epidemiologia; surtos de doença. 
$\mathrm{T}$ he field of global health history has attracted practitioners from an array of disciplines, including biography, biomedicine, institutional history, medical anthropology, medical history, political history, and transnational history. As the sheer range of these disciplines might suggest, there are divergent opinions about what global health history is or should be. Moreover, there are divergent opinions about when global health history began - some scholars might prefer the end of the Cold War in 1991, the creation of the World Health Organization in 1948, the creation of the Health Commission of the League of Nations in 1920, the founding of the International Health Commission of the Rockefeller Foundation in 1913, or an earlier date - and consequently how global health history might best be periodized.

Many scholars have drawn upon research from beyond their own disciplines, and the diverse approaches have produced a rich, hybrid literature informed by multidisciplinary perspectives and insights. Yet for a field whose name suggests that one of its central concerns must be the history of health interventions, there has been a relative dearth of interest in the epidemiological dimensions of global health initiatives; that is, the empirical impacts of global health interventions on population health and the ways in which health interventions have transformed patterns of disease transmission.

The historical epidemiological approach itself, however, is not new. Its proximate roots can be traced to the work of world historians in the late 1960s and 1970s who explored historical disease processes. In 1968, Philip D. Curtin wrote an influential essay on the epidemiology of the Atlantic slave trade that changed our understandings of the historical demography of the New World plantations and the disease conditions that European traders encountered along the western coast of Africa (Curtin, 1968). In 1972, Alfred W. Crosby, Jr. explored the historical impact of Eurasian diseases introduced to the Americas on Native American populations in The Columbian exchange: the biological and cultural consequences of 1492 (Crosby, 1972). In 1976, William H. McNeill, in Plagues and peoples, authored a foundational text on the global history of infectious disease processes, which became widely known among students of public health and medicine (McNeill, 1976).

In recent years, there has been new interest in exploring the historical epidemiology of contemporary disease challenges using contemporary biomedical understandings. Scholars of Africa have been in the forefront. Some notable examples are William H. Schneider's The history of blood transfusion in Sub-Saharan Africa (Schneider, 2013), which establishes an evidentiary baseline that casts new light on the history of HIV transmission; the edited collection Global health in Africa: historical perspectives on disease control (Giles-Vernick, Webb Jr., 2013); and Jennifer Tappan's The riddle of malnutrition: the long arc of biomedical and public health interventions in Uganda (Tappan, 2017).

The subdiscipline of historical epidemiology will accommodate a variety of methodological approaches. The nature of evidence about health interventions is varied and uneven. Historical epidemiological studies can draw upon the surviving record of investigations carried out during the course of health interventions and/or investigations that were carried out retrospectively, and scholars can leverage contemporary biomedical understandings to develop more nuanced assessments of the health impacts of historical interventions. As with other types of historical analysis, our understandings of the impacts 
of past health interventions will change over time. The call here is to encourage scholars to use contemporary biomedical understandings to illuminate the historical record.

\section{Historical epidemiology and contemporary disease challenges}

The reason that this subject area is little developed seems readily apparent: depending upon the questions to be investigated, research in historical epidemiology might require competencies in some of the public health sciences, such as epidemiology, immunology, bioethics, or parasitology, and in some of the subdisciplines of history, such as economic history, demography, or medical history, as well literacy in the medical anthropology and biomedical literatures. In this respect, it would demand an academic crossing of the boundaries that define disciplinary and interdisciplinary knowledge. Although it is common for public health specialists to be familiar with the range of the public health sciences and for historians to be familiar with the range of the historical subdisciplines, few public health specialists have training in history and vice versa. The tide, however, appears to be turning. Some younger historians are seeking training in public health, and some philanthropic organizations, such as the WellcomeTrust, and some national research organizations, such as the Swiss National Science Foundation, are funding global health historians to engage with aspects of the epidemiological past that bear upon contemporary disease challenges.

This is to the good. The subdisciplineof historical epidemiology will allow global health historians to bridge the chasm between the study of historical disease outbreaks and the work of contemporary global health practitioners. It holds the promise of creating a more robust and more nuanced foundation for global public health decision-making by deepening the empirical record from which we draw lessons about past interventions. It will unearth past successes and failures that may suggest alternative or hybrid approaches to the control of epidemic or endemic disease processes.

This essay will draw upon historical epidemiological research on three global public health campaigns to illustrate this promise. The first is the Rockefeller Foundation's efforts to control hookworm disease. Its program began in the southern USA (1909-1914) and was expanded overseas in the 1910s and 1920s into the Caribbean, South America, South Asia, Southeast Asia, and East Asia. Its goal was to reform open defecation practices in order to end the transmission of soil-transmitted helminthic infections. It ended with an acknowledgment that hookworm infections - and by extension other soil-transmitted helminthic infections - could not be controlled through mass drug administration (MDA). The second campaign was that undertaken by the World Health Organization (WHO) against malaria in tropical Africa. This was part of the WHO's Global Malaria Eradication Program that was formally launched in 1955 and was closed down in 1969. In tropical Africa, the WHO directed pilot malaria eradication projects that focused on the need to develop protocols that could fully interrupt malaria transmission and might be scaled up across the continent. The African projects ended with the acknowledgment that indoor residual spraying with synthetic insecticides alone or in combination with mass antimalarial drug administration would not fully interrupt malaria transmission on a sustainable basis. The third case is that of successive international efforts to shut down the transmission of 
Ebola virus disease during outbreaks in tropical Africa. In the most severe outbreak, in 2013-2015 in Guinea, Liberia, and Sierra Leone, the most effective interventions were those undertaken in collaboration with local communities to support "safe" burial practices that reduced the possibility of viral transmission, in combination with the biomedical response mounted by national and international actors. The socio-cultural interventions, however, were not introduced during the early stages of the international response, and this was a major factor contributing to the rapid increase in infections that spiraled out of control. I have chosen these examples to illustrate that historical epidemiology may be directly useful to those who are engaged in global public health interventions.

\section{Historical epidemiology and the control of soil-transmitted helminthic infections}

Soil-transmitted intestinal worms - hookworm, roundworm, and whipworm - are among the most common human infections (Webb Jr., 2020). By a 2010 estimate, the number of people infected by hookworm was in the range of 576-740 million, roundworm approximately one billion, and whipworm about three-quarters of a billion (Brooker, 2010). All three worm infections are transmitted by eggs that are passed in the feces of infected individuals. Hookworm larvae develop in polluted soil and typically attach themselves to human feet or hands through dermal contact. Roundworm and whipworm eggs are ingested via an oral-fecal route. All three worms make their way to the human intestines. Once there, hookworms and whipworms attach themselves to the intestinal walls and draw blood; roundworms draw their sustenance from other nutrients in the intestines. The universal disposal of feces in latrines or by other sanitary means fully breaks the cycle of transmission (US CDC, 15 Feb. 2018; 10 Jan. 2013a; 10 Jan. 2013b).

In Europe, physicians had long been familiar with an illness characterized by the symptoms of anemia and listlessness (Khalil, 1922; Dubini, 1843). Known as miner's disease, it was a common affliction of those who worked underground. In the late nineteenth century, this illness was also diagnosed in laborers who dug tunnels through the Alps, and it soon became apparent that hookworm disease was more widely distributed than had been previously recognized. Researchers using microscopy examined fecal smears from agricultural workers as well as those who labored underground and identified the hookworm species Ancylostoma duodenale in their samples (Nauss, 1921; Mathias, 1898; Palmer, 2010).

In 1909, the newly created Rockefeller Sanitary Commission for the Eradication of Hookworm Disease (RSC) launched a campaign against hookworm disease in the southern US, where preliminary surveys had shown a high prevalence of hookworm infestation, if not outright hookworm disease (Ettling, 1981). The goal of the RSC was to build popular consensus for the creation of departments of public health that would proselytize for improved sanitation. Toward this end, the RSC dispensed chemical therapy to hookworm suffers who assembled at temporary clinics and mounted public demonstrations of how to build a latrine ("privy"). The success of the RSC was partial at best. Those most involved in the effort were dumbfounded when the Rockefeller Foundation declared victory over hookworm disease and ended the work of the RSC in 1914 (Stiles, 1939). 
The Rockefeller Foundation then created its International Health Board (later renamed the International Health Division, IHD) to undertake campaigns to treat hookworm disease and to promote "sanitation" - i.e., improved excreta disposal - outside the US (Palmer, 2010). The campaigners worked in a variety of different socio-cultural and ecological environments, including northeastern Brazil, southern India, and China. They racked up new findings about hookworm transmission along the way. Some findings were general. The campaigners learned that chemical therapy would not clear all hookworm infections, and that, absent a change in open defecation practices at the community level, the rates of reinfection among those treated with chemical therapy were high. Moreover, the anti-hookworm campaigners found that they were unable to mobilize the support of governments for the reform of open defecation practices. Some findings were regionally specific. For example, in southern India, they found that high rates of hookworm infestation did not mean that there were high rates of hookworm disease (Mhaskar, 1924). In Malaya, the IHD discovered that both malaria and hookworm were prevalent and that both caused anemia. Because it was cost-prohibitive to determine the cause of the anemia in individual sufferers and to treat hookworm with chemical therapy and purgatives and malaria with antimalarial alkaloids, this constituted an insuperable barrier to appropriate treatment (Darling, Barber, Hacker, 1920). Some treatment campaigns achieved successes in hookworm disease reduction, but they were discontinued in the 1920s on the emerging general principle that sanitation programs were foundational for success in eliminating hookworm disease. Sanitation had to come first; curative treatment could only be effective when the prospects for re-infection were greatly reduced. At length, confronted with cultural resistance to their calls to change open defecation practices, a lack of political will among state authorities to proselytize for improved excreta disposal, and the economic logic of using human waste as fertilizer (particularly in East and Southeast Asia), the Rockefeller Foundation quietly shuttered its overseas operations (Farley, 2004).

In the first decade of the twenty-first century, under the rubric of "Neglected tropical diseases," global health organizations re-engaged the struggle against all three soiltransmitted helminth infections: hookworm, roundworm, and whipworm. The new campaigners have rolled out MDA programs for school-age children with safe drugs subsidized by pharmaceutical companies. The goal has been to reduce the disease burden of helminthiasis.

The programs undoubtedly improve the health of those who have worm burdens sufficiently high to cause disease symptoms. However, other presumed benefits, including improved nutritional status and improved school performance, now appear to be largely illusory (Taylor-Robinson et al., 2015). Because it is not feasible to test individuals to determine the extent of the worm burden or measure the timing and extent of re-infection, the health gains are not quantifiable. Moreover, it is clear that there are significant gaps in coverage. Because treatment is principally doled out in schools, the campaign does not reach younger children who are particularly at risk of infection. There have been no coordinated efforts to improve excreta disposal, either before or during the campaigns.

Today, scientific understandings of the health consequences of light helminthic infections are substantially different from those of a century ago. Contemporary research 
suggests that light infections may improve some aspects of the immune response to hyperinflammatory diseases such as inflammatory bowel disease and multiple sclerosis. Some researchers view the large-scale deworming of tropical populations as an opportunity to investigate prospectively the impact of vermifuges on the prevalence of allergic or other inflammatory diseases. This suggests that deworming programs might lead to the emergence of inflammatory or metabolic conditions that could assume epidemic proportions in countries with weak health systems that are unprepared for this challenge, prompting experts to call for studies to assess this risk (Wammes et al., 2014).

There are other concerns as well. The efforts to control helminthiasis through mass drug administration are now confronted by the emergence of helminthic drug resistance (Choffnes, Relman, 2011). It is clear that the MDA approach alone cannot eliminate intestinal worm transmission, yet in many regions of the global South, it continues apace (De Silva et al., 2003).

Considered from an historical perspective, the efforts of the contemporary campaigns against soil-transmitted helminthic infections have been compromised by their unfamiliarity with the basic lesson learned in the course of the RSC and IHD campaigns in the early decades of the twentieth century: there can be no victory in the battle against soil-transmitted helminthic infections until public health services engage successfully with the basic issue of improved excreta disposal.

\section{Historical epidemiology and malaria control in tropical Africa}

Malaria has been one of the principal disease burdens in human history (Webb Jr., 2014). The heaviest burden in the past, as today, has been in tropical Africa. Although the earliest chapters of malaria's history in Africa are indistinct, it appears that the disease pressure, in a distant era before the agricultural revolution, was high, and that it selected for genetic mutations such as Duffy antigen negativity and sickle cell hemoglobin that protected the bearers against vivax and falciparum malaria, respectively (Webb Jr., 2009). Some African societies discovered natural medicines that could reduce the suffering of the afflicted, although until the late-nineteenth-century discovery that anopheline mosquitos were the vectors of malaria, there was little that could be done to reduce the transmission of the parasites.

Early mosquito control came to tropical Africa with the first missions of the Liverpool School of Tropical Medicine. The first efforts were aimed at protecting European traders, soldiers, and administrators along the West African coast. Mosquito control squads destroyed mosquito larvae in coastal cities with short-term effect. Soon thereafter, in regions in which the topography proved suitable, European communities relocated to higher elevations above the flight ranges of the mosquitos. In other regions, Europeans established patterns of residential segregation in the belief that African children were major carriers of the malaria parasites and that physical separation from African domiciles was the key to protecting European health (Christophers, Stephens, 1900). Europeans also believed that most African adults were not particularly vulnerable to malaria, mistaking the acquired immunity that frequent sufferers of malaria developed for a simple lack of susceptibility. 
These beliefs initially masked the high rate of mortality in African children under the age of five years from malaria infections.

By the 1930s, at least in some regions, the mask was falling away. Physicians in the Belgian Congo were treating African children with a new protocol that dramatically reduced childhood mortality from malaria. Children were given antimalarial therapy intermittently, whether or not they had any symptoms of malaria (Duren, 1937) (Today, this is known as intermittent preventive therapy for children, or iPTc). Among the cohorts of children under the physicians' care, mortality plummeted. Alas, news of the success in the Belgian Congo did not diffuse widely.

Toward mid-century, the success story in the Belgian Congo was utterly eclipsed by the shattering experience of the Second World War. During the course of the conflict, the Americans and British Allies began to make use of the new synthetic insecticide known as DDT, which proved astonishingly effective in killing the anopheline mosquitos and a host of other insect pests and rodents. It no longer seemed necessary to focus primarily on treatment: DDT would "prevent" infections. A new era was opening, a paradigm shift had begun, and the lessons of the past seemed no longer relevant. Why linger over the partial successes of the past when a new chemical tool was available whose use might portend the eradication of malaria (Harrison, 1978; Litsios, 1996)?

A series of DDT interventions were launched in the immediate postwar period, and in a highly contentious WHO meeting held in Kampala in 1950, malaria experts decided that, even in the face of imposing logistical and political obstacles and malariological concerns that the efforts might compromise the acquired immunity of affected populations, the WHO should make a commitment to using DDT in Africa in an effort to reduce the burden of malaria. A number of pilot projects were initiated in an effort to develop malaria eradication protocols that would work in different African ecological settings (Webb Jr., 2014).

During the mid-1950s, the World Health Organization launched a global malaria eradication program (Nájera, 2001; Packard, 2007). The program did not achieve its objective of global malaria eradication and thus was judged a political failure, but by the standards of ordinary public health metrics it was highly successful. The global malaria eradication program brought down malaria mortality and morbidity in many world regions by a full order of magnitude. The independent states and European colonies in tropical Africa did not fully participate in the global eradication program because malaria specialists, based upon the early pilot projects, advised that the prospects for nation - or colony-wide eradication were poor. Nonetheless, the WHO continued to support many large-scale pilot projects in tropical Africa in an effort to determine an approach that could reduce malaria transmission to zero.

The pilot projects made extensive use of synthetic insecticides - first DDT and then others when insecticide resistance emerged. When synthetic insecticides proved insufficient to interrupt transmission, the project dispensed antimalarials in mass drug administration programs. The drugs were effective in driving down malaria morbidity and mortality (although some produced parasite resistance quickly), but like the synthetic insecticides their use was unable to fully interrupt and sustain the interruption of malaria transmission. 
The overall picture, thus, was that the pilot projects achieved remarkable short-and mediumterm successes in reducing malaria transmission to near zero, but they were not able to end it (Webb Jr., 2014).

There were some untoward negative consequences. In Liberia, for example, the pilot projects had maintained very low transmission levels for years, with the result that when they ended, the acquired immunity of the populations in the protected zones had deteriorated. When the interventionists packed up and left, epidemic malaria ripped through the populations (Webb Jr., 2011).

In the years following the closure of the pilot projects, the antimalarial drug chloroquine became increasingly available in Africa at a price that most sufferers could afford. Chloroquine was taken principally as a curative drug, although often in partial courses of treatment. It had the effect of reducing the overall levels of malaria mortality in Africa until the late 1980s, when resistance to chloroquine emerged and there was no back-up drug in the pipeline.

The pilot malaria eradication projects in tropical Africa never expanded into full national programs. During the 1960s, 1970s, and 1980s, most of the independent African governments prioritized economic development schemes, and the ready access to chloroquine meant that the problem of malaria loomed less large. The upshot was that a generation of malaria eradication efforts in tropical Africa went forgotten. By the early twenty-first century, it was common in scientific publications on malaria for authors to assert that Africa had been excluded from the global malaria eradication program, with no reference to the pilot projects that had protected an estimated 14 million people. The implication, following the 2007 announcement of the Bill and Melinda Gates Foundation's initiative to eradicate malaria, was that malaria eradication efforts in tropical Africa would be launched more or less de novo.

New tools had important roles in the new campaign. Campaigners rolled out insecticide-treated bednets widely across the continent with the goal of high coverage, and rapid diagnostic tests, which allowed for immediate diagnosis (without microscopy) and consequently rapid treatment, became newly available in clinics. A new generation of artemisinin-based antimalarial drugs proved highly effective. Old tools were sharpened. DDT and other residual insecticides were deployed, sometimes in rotation to slow down the emergence of mosquito resistance. But new tools in combination with old tools worked the same ground to much the same effect (Webb Jr., 2014). With the exception of some areas of weak endemicity in southern Africa, it was not possible to achieve zero transmission. In the past several years, progress has stalled, and in some regions, malaria transmission has increased.

The twenty-first century antimalaria campaigners in tropical Africa were frequently unaware that they were involved in repetitions of the programs of the mid-twentieth century. Consider the issue of vector control in West Africa. Beginning in the immediate post-Second World War period and continuing into the 1960s, malaria control and eradication programs in West Africa used an array of synthetic chemicals as larvicides (to kill mosquito larva and pupae) and insecticides (to kill adult mosquitos). Initially, DDT 
was the synthetic chemical of choice, but there were early problems with its adsorption on building materials during indoor residual spraying programs, and the malariologists discovered that the application of DDT soon selected for resistance in the anopheline vectors of many regions in West Africa. The malaria campaigns turned to other more dangerous insecticides such as DLD (Dieldrin) and HCH (Lindane), but these insecticides also selected for resistance. After a few years, the spraying campaigns were abandoned because they had stopped working (Webb Jr., 2014).

During the current malaria eradication campaigns, the US Centers for Disease Control (CDC) malaria teams began to use the same synthetic insecticides in the same West African regions on the same mosquito populations, unaware that there had been an earlier intervention. This was striking because in Liberia the CDC had spearheaded the use of indoor residual spraying in West Africa in 1945 and continued with malaria eradication programs into the 1960 s. $^{1}$

There was a similar amnesia about the historical record of chemoprophylaxis. During the pilot malaria eradication projects of the 1950s and 1960s, when the synthetic insecticides did not fully interrupt malaria transmission, the campaigners had turned to mass drug administration with antimalarial drugs, including pyrimethamine, chloroquine, and primaquine. Pyrimethamine was highly effective in clearing infections, but it had selected for parasite resistance within a year of its use in MDA. Chloroquine proved the superior drug, and the campaigners decided to combine chloroquine with primaquine, a drug that could eliminate the malaria gametocytes and thus make it impossible for a mosquito biting a person infected with malaria to transmit the parasite to another.

By 2014, the Bill and Melinda Gates Foundation had developed plans for an MDA program in Africa that would use primaquine. They were unaware that primaquine had been used in the earlier malaria eradication campaigns. Had they known, they would have conducted due diligence in determining where primaquine had been administered and to which populations. A single dose of primaquine in a lifetime is considered safe for all, but for those who carry the G6PD genetic mutation (the most common genetic mutation in human beings), a second dose of primaquine may be dangerous, possibly producing illness or even death. Among those slated for MDA were almost certainly some elder individuals who had received primaquine in the earlier campaigns. When the Gates Foundation authorities belatedly became aware of this issue, they rushed to organize a meeting of historians and malaria specialists to gather information about the historical use of primaquine in Africa. ${ }^{2}$

These two examples - from the CDC and the Gates Foundation - illustrate the fact that some global health interventions are launched without adequate knowledge of previous disease control efforts in the same region, against the same pathogens, using the same or similar tools. They suggest that the study of past public health interventions can improve contemporary campaigns by allowing them take advantage of past experiences. In some cases, the study of historical epidemiology may protect vulnerable populations from potentially dangerous health interventions. 


\section{Historical epidemiology and emerging infectious diseases: Ebola}

Ebola virus disease (EVD) is a highly lethal viral hemorrhagic fever spread through contact with infected bodily tissues and fluids that affects human beings and non-human primates. ${ }^{3}$ The animal reservoir or reservoirs for the four different Ebola virus species (Zaire, Sudan, Bundibugyo, and Taï Forest) that infect human beings are unknown, although African fruit bats are likely candidates. Humans have principally contracted the virus from infected primates through bushmeat hunting and from other infected humans by caring for individuals with EVD, preparing EVD victims for burial, and the laying-on of hands on EVD victims during burial ceremonies as a sign of respect.

Since the first known outbreaks in 1976, the CDC has catalogued a total of 35 outbreaks of EVD in tropical Africa over the forty-year period from 1976 to 2015. This period includes a fourteen-year stretch (1980-1993) with no recorded outbreaks (WHO, n.d.). The list of outbreaks is almost certainly incomplete, however, because cases may occur without being reported, such as in 1997, when the medical anthropologists Barry and Bonnie Hewlett discovered evidence of an outbreak of Ebola in Gabon earlier that year that had been unreported (Hewlett, Hewlett, 2008). Several epidemiological sero-surveys, for example, have reported the high prevalence of Ebola antibodies in communities in the absence of reports of Ebola outbreaks (Becquart et al., 2010; Gonzalez et al., 2000; Busico et al., 1999). Immunoglobulin $\mathrm{G}$ antibodies (the most common type of antibody that is found in all bodily fluids) are known to cross-react amongst Ebola species (MacNeil, Reed, Rollin, 2011), and thus this high seroprevalence may be the outcome of exposure to as yet unknown less pathogenic or non-pathogenic variants of Ebola virus (Muyembe-Tamfum et al., 2012).

Clinical diagnosis of EVD has proved difficult. The symptoms of EVD are similar to those of some other diseases, and this fact also supports the hypothesis of non-reporting. The 1994 EVD outbreaks were first reported as yellow fever, based on serological analyses of samples but without isolation of the virus (Amblard et al., 1997). An outbreak in late 1994 to early 1995 in Makokou General Hospital in northeastern Gabon was first identified as yellow fever, and a program of vaccination was initiated. Retrospectively, researchers discovered that Ebola virus was concomitantly present with yellow fever virus (Georges et al., 1999).

In the decades following the first reported outbreaks, virologists and ecologists investigated the Ebola reservoirs (with little definitive success), and virologists discovered the four different Ebola species that can infect human beings. The epidemiologists concentrated on index cases guided by the belief that human encroachment into nonhuman primate environments and the practice of bushmeat hunting were responsible for viral spillover (although this may not have been the case in two outbreaks in Sudan that occurred in a cotton factory). In most outbreaks the source of the human index case was not identified. This was true of all the outbreaks occurring from 1976 to 1979, the outbreaks of Mekouka (Gabon) in 1995, Booué (Gabon) in 1996, Kikwit (Democratic Republic of the Congo) in 1995, and all the outbreaks of Ebola-Sudan in Sudan (1976, 1979, and 2004) and Uganda (2000) (Pourrut et al., 2005). Researchers found commonalities in the patterns of transmission in cases of infection subsequent to the index cases. In the 
first 1976 outbreak in Sudan, as in many later outbreaks, the hospital was a principal site of amplification. The transmission of the disease was associated with the nursing care of the sick (Francis et al., 1978).

Early in the twenty-first century, more than 25 years after the first outbreak, the WHO sought the involvement of medical anthropologists to help understand the African responses to the Ebola outbreaks. The medical anthropologists Barry Hewlett and Bonnie Hewlett discovered that cultural practices of preparing the dead for burial (when the viral loads in the deceased bodies were extremely high) were a major contributor to the spread of Ebola virus infection (Hewlett, Hewlett, 2008). Yet their findings, and similar findings of Pierre Formenty and other medical anthropologists, had little influence on the practical use of medical anthropology in Ebola outbreaks (Formenty et al., 2003; Hewlett, Amola, 2003). This was, arguably, in part, because only a very small number of anthropologists had experience with Ebola. In any event, no global health resources were devoted to developing a cadre of anthropologists who had a specialization in Ebola control. This oversight had devastating consequences in the early stages of the West African epidemic. The public health messages focused on the imperative to avoid bushmeat to the exclusion of messages about the imperative for safer burial practices. The burials of EVD victims who were of high status served as super-spreader events (Richards, 2016).

The 2013-2015 EVD epidemic in West Africa was remarkably different from earlier outbreaks in its duration, spatial extent, number of cases, number of deaths, and the nature of the international response. The first case was in a sparsely populated village in Guinea in December 2013, and in March of 2014 the government of Guinea reported new cases of EVD. The epidemic then spread to Sierra Leone and Liberia, with scattered cases elsewhere in West Africa - in Senegal (one case), Mali (eight cases), and Nigeria (20 cases) - and in North America and Europe - in Spain (one case), Italy (one case), the United Kingdom (one case), and the USA (four cases). Within Guinea, Sierra Leone, and Liberia, the EVD epidemic spread into highly populated urban settings. There were more than 28 thousand confirmed cases and more than 11 thousand deaths.

Until the 2013-2015 West African epidemic, EVD was held to be a highly dangerous emerging infection with a limited ability to spread. In the aftermath of the epidemic, this judgment had to be revised. Ebola is now considered to be a highly dangerous emerging infection that poses a great risk to both urban and rural populations and one that has the potential to cross over national boundaries to produce a transregional epidemic. An outbreak of EVD in the Democratic Republic of the Congo in August 2018 has continued into May 2019 (as of this writing), and according to recent reports the outbreak has surged out of control. More than 1,300 confirmed or probable cases have been recorded, and close to nine hundred deaths have been attributed to EVD (Tsongo, Ratcliffe, 2019). In March 2019, the director of the CDC projected that the outbreak might not be contained for a year (Grady, 16 Mar. 2019).

Since the epidemic, international health agencies have tried to assess the effectiveness of their responses to the EVD epidemic. Much of the focus has been on how to improve data-sharing between organizations in the midst of a public health crisis. There is a 
perceived need for sharing clinical data on Ebola virus disease to help in diagnosis and in the epidemiological and molecular domains (Maxmen, 2017; Modjarrad et al., 2016). There has been little effort to integrate community engagement data into epidemiological modeling, although it appears that this data is critically important to accurate forecasting and the allocation of resources (Abramowitz, 2017). Medical anthropology remains the poor step-child of the epidemic response teams. Indeed, in the course of the current EVD outbreak in the Democratic Republic of the Congo, one of the signal failures identified by the Ebola response teams was their inability to effectively communicate with the communities that were afflicted with EVD (Grady, 7 Mar. 2019).

A deeper historical epidemiological analysis of the responses during the various EVD outbreaks would be useful in determining the value of developing a more effective, multidisciplinary response that reaches beyond the biomedical sciences. This brief review suggests that community-health messaging should have a central role in the epidemic response. As more historical epidemiological research on Ebola responses is carried out, it may be possible to estimate more precisely the impacts of culturally appropriate public health messaging on the reduction of EVD transmission.

\section{The promise of historical epidemiology}

At this transitional moment in medical history in the academy, when the rubric of "medical humanities" is ascendant, it will be propitious for medical historians to develop the field of historical epidemiology in order to integrate perspectives from epidemiology, ecology, medical anthropology, biomedicine, and public health with the goal of improving contemporary disease control interventions.

One broad path will be through the reinsertion of lost public health knowledge into contemporary debates. Consider, for example, the conundrum of how best to counter the health threats posed by the Aedes aegypti and Aedes albopictus mosquitos. These mosquitos spread Zika virus, yellow fever, dengue fever, and chikungunya. To date, the thrust of the global health research community has been to devote monies to the development of vaccines. This might well seem to be the best and most reasonable approach. Yet the historical experience with anti-viral vaccines has been little interrogated, and what is known suggests some strongly cautionary lessons. For example, we have had a highly effective vaccine against yellow fever since 1932, but it has been administered irregularly (and in some cases not at all) to major populations at risk. This is the background to the recent 2016 outbreak of yellow fever in Angola, Uganda, and the Democratic Republic of the Congo, which spread through the vast unimmunized populations of these African states. A related point can be made about the history of vector control. With the rise of molecular science, vector control has experienced a loss of prestige, to the extent that it is frequently neglected in the deliberations over disease control. Yet we have had, for example, about 100 years of intermittent vector control in the Americas that has targeted Aedes aegypti, and a few generations ago this mosquito threat seemed on the verge of elimination in the western hemisphere (Webb Jr., 2016). Historical epidemiological studies can bring these historical experiences into our contemporary public health deliberations. 
Historical epidemiology may make contributions to our understandings of infectious disease processes by situating them in historical ecological processes. For example, the powerful forces of biome conversion, forced resettlement, and urbanization have long altered the conditions in which infectious diseases can be transmitted, and depending upon the pathogen these forces may have amplified or suppressed transmission. As examples, one might note that in tropical Africa the processes of rapid urbanization have concentrated a demand for bushmeat in the cities, and thereby increased the prospects for the introduction of zoonotic pathogens from their wild animal hosts and the amplification of transmission. Refugee camps, without adequate provisions for the treatment of human waste, have facilitated the transmission of diseases transmitted by a fecal-oral route, and cholera has thereby become an endemic disease in Africa. The pollution of water sources in some of the major peri-urban areas has reduced the transmission of malaria - because the vector mosquitoes need clean water in which to breed - while at the same time augmenting water-borne pathogens and generating a "toxic fringe" around the cities.

Yet another fertile field of inquiry will be the impacts of the various disease control interventions on broader ecologies. The current malaria control campaigns, for example, are operating in an environment that has been significantly altered by the WHO's global malaria eradication campaign. The earlier campaign's use of synthetic insecticide selected for alleles in the vector mosquitoes that provide resistance to the synthetic insecticides, and it is likely that the mix of vector mosquitoes was significantly altered by the disease control interventions. Indoor residual house spraying - and today, during the contemporary campaign, insecticide-treated bed nets - produced heavy selection pressure on indoor-biting mosquitoes and may have forced the evolution of outdoor-biting anopheline mosquitoes. In this respect, historical epidemiological studies may suggest the need for new ways of assessing the biological constraints under which contemporary disease control projects are working. A concomitant impact may be felt in the field of ecological studies, as it becomes evident that some elements of the ecological worlds in which the campaigns operate are themselves, in part, the artifacts of past interventions.

\section{Final considerations}

To date, the earlier programs of disease control have been largely overlooked, and these histories need to be investigated in order to better evaluate the impacts of past programs on processes of disease transmission and population health. The exact benefits can only be revealed by additional research, but a range of possible benefits can be suggested. Historical knowledge about past campaigns might act as a brake on the re-launching of similar approaches that have not achieved their stated goals in the past; halt initiatives that might produce unwanted outcomes; suggest new roles for neglected approaches that achieved success in the past; and open new avenues for scientific exploration. 


\section{NOTES}

${ }^{1}$ In April 2012, when I made a presentation to the entomologists at the US Centers for Disease Control in Atlanta, Georgia, no one in the malaria division of the CDC had heard of the first-generation Liberian projects, and there were no archives at the CDC of materials about these campaigns.

2 The meeting took place in Seattle at the Gates Foundation headquarters in September 2014.

${ }^{3}$ This section is based upon research conducted for a 2018 Wellcome Trust project "Data sharing in public health emergencies: anthropological and historical perspectives on data sharing during the 2014-2016 Ebola epidemic and the 2016 yellow fever epidemic."

\section{REFERENCES}

ABRAMOWITZ, Sharon.

Epidemics (especially Ebola). Annual Review of Anthropology, v.46, p.421-445. 2017.

AMBLARD, Jacques et al. Identification of the Ebola virus in Gabon in 1994. Lancet, v.349, n.9046, p.181-182. 1997.

BECQUART, Pierre et al.

High prevalence of both humoral and cellular immunity to Zaire Ebolavirus among rural populations in Gabon. PLoS One, v.5, n.2, e9126. 2010.

\section{BROOKER, Simon.}

Estimating the global distribution and disease burden of intestinal nematode infections: adding up the numbers: a review. International Journal of Parasitology, v.40, n.10, p.1137-1144. 2010.

BUSICO, Kristina M. et al. Prevalence of IgG antibodies to Ebola virus in individuals during an Ebola outbreak: Democratic Republic of the Congo, 1995. The Journal of Infectious Diseases, v.179, supp.1, p.S102-S107. 1999.

CHOFFNES, Eileen R.; RELMAN, David A. (Rapporteurs).

The causes and impacts of neglected tropical and zoonotic diseases: opportunities for integrated intervention strategies: workshop summary. Washington: National Academies Press. 2011.

CHRISTOPHERS, Samuel Rickard; STEPHENS, John William Watson.

The native as the prime agent in the malarial infection of the Europeans. In: Royal Society (Great Britain). Further reports to the malaria committee of the Royal Society. London: Harrison and Sons. p.21-24. 1900.

CROSBY JR., Alfred W.

The Columbian exchange: the biological and cultural consequences of 1492. Westport: Greenwood. 1972.

CURTIN, Philip D.

Epidemiology and the slave trade. Political Science Quarterly, v.83, n.2, p.190-216. 1968.
DARLING, Samuel Taylor; BARBER, Marshall Albert; HACKER, H.P.

Hookworm and malaria research in Malaya, Java, and the Fiji Islands: report of Uncinariasis Commission to the Orient, 1915-1917. New York: Rockefeller Foundation/International Health Board. 1920.

DE SILVA, Nilanthi R. et al.

Soil-transmitted helminth infections: updating the global picture. Trends in Parasitology, v.19, n.12, p.547-551. 2003.

DUBINI, Angelo.

Nuovo verme intestinal umano (Agchylostoma duodenale) constituente un sesto genere dei nematoide apropri del l'uomo. Annali Universali de Medicina, v.106, p.5-13. 1843.

DUREN, Albert.

Un essai d'étude d'ensemble du paludisme au Congo Belge. Institut Royal Colonial Belge, Section des sciences naturelles et médicales. Mémoires, v.5, n.5, p.1-87. 1937.

ETTLING, John.

The germ of laziness: Rockefeller philanthropy and public health in the new south. Cambridge: Harvard University Press. 1981.

FARLEY, John.

To cast out disease: a history of the International Health Division of the Rockefeller Foundation (1913-1951). New York: Oxford University Press. 2004.

FORMENTY, Pierre et al. Epidémie de fièvre hémorragique à virus Ebola en République du Congo, 2003: une nouvelle stratégie. Médicine Tropicale, v.63, p.291-295. 2003.

FRANCIS, Donald P. et al. Ebola fever in the Sudan, 1976: epidemiological aspects of the disease. In: Pattyn, S.R. (Org.). Ebola virus haemorrhagic fever. Amsterdam: Elsevier; North-Holland Biomedical Press. p.100-104. 1978. 
GEORGES, Alain-Jean et al.

Ebola hemorrhagic fever outbreaks in Gabon, 1994-1997: epidemiologic and health control issues. The Journal of Infectious Diseases, v.179, supp.1, p.S65-S75. 1999.

GILES-VERNICK, Tamara; WEBB Jr., James L.A. (Ed.).

Global health in Africa: historical perspectives on disease control. Athens: Ohio University Press. 2013.

\section{GONZALEZ, Jean Paul et al.}

Ebola and Marburg virus antibody prevalence in selected populations of the Central African Republic. Microbes and Infection, v.2, n.1, p.3944. 2000.

GRADY, Denise.

Ebola epidemic in Congo could last another year, CDC director warns. New York Times. 16 Mar. 2019.

GRADY, Denise.

The battle against one of the worst Ebola epidemics ever is in trouble. New York Times. 7 Mar. 2019.

HARRISON, Gordon.

Mosquitos, malaria and man: a history of the hostilities since 1880. New York: E.P. Dutton. 1978.

HEWLETT, Barry S.; AMOLA, Richard P.

Cultural contexts of Ebola in northern

Uganda. Emerging Infectious Diseases, v.9, n.10, p.1242-1248. 2003.

HEWLETT, Barry S.; HEWLETT, Bonnie L. Ebola, culture, and politics: the anthropology of an emerging disease. Belmont: Thomson Wadsworth. 2008.

KHALIL, Mohamed.

An early contribution to medical

helminthology, translated from the writings of the Arabian physician Ibn Sina (Avicenna) with a short biography. Journal of Tropical Medicine and Hygiene, v.25, p.65-67. 1922.

LITSIOS, Socrates.

The tomorrow of malaria. Karori: Pacific Press. 1996.

MACNEILL, Adam; REED, Zachary; ROLLIN, Pierre E.

Serologic cross-reactivity of human IgM and IgG antibodies to five species of Ebola virus. PLoS Neglected Tropical Diseases, v.5, n.6, e1175. 2011.

MATHIAS, James.

An epidemic of ankylostomiasis. South African Medical Journal, v.6, p.108-111. 1898.

MAXMEN, Amy.

Massive Ebola data site planned to combat outbreaks. Nature, v.549, n.7670, p.15. 2017.
MCNEILL, William H.

Plagues and peoples. New York: Anchor. 1976.

MHASKAR, Krishnaji Shripat.

Report of the ankylostomiasis inquiry in Madras. Indian Medical Research Memoirs, n.1. 1924.

MODJARRAD, Kayvon et al.

Developing global norms for sharing data and results during public health emergencies. PloSMedicine, v.13, n.1, e1001935. 2016.

MUYEMBE-TAMFUM, Jean-Jacques et al. Ebola virus outbreaks in Africa: past and present. Onderstepoort Journal of Veterinary Research, v.79, n.2, p.6-13. 2012.

NÁJERA, José Antônio.

Malaria control: achievements, problems, and strategies. Parassitologia, v.43, n.1-2, p.1-89. 2001.

NAUSS, Ralph W.

Hookworm in California gold mines. American Journal of Public Health, v.11, n.5, p.439-451. 1921.

PACKARD, Randall M.

The making of a tropical disease: a short history of malaria. Baltimore: Johns Hopkins University Press. 2007.

PALMER, Steven.

Launching global health: the Caribbean odyssey of the Rockefeller Foundation. Ann Arbor: University of Michigan Press. 2010.

POURRUT, Xavier et al.

The natural history of Ebola virus in Africa. Microbes and Infection, v.7, n.7-8, p.1005-1014. 2005.

RICHARDS, Paul.

Ebola: how a people's science helped end an epidemic. London: Zed Books. 2016.

SCHNEIDER, William H.

The history of blood transfusion in sub-Saharan Africa. Athens: Ohio University Press. 2013.

STILES, Charles Wardell.

Early history, in part esoteric, of the hookworm (uncinariasis) campaign in our southern United States. Journal of Parasitology, v.25, n.4, p.283308. 1939.

TAPPAN, Jennifer.

The riddle of malnutrition: the long arc of biomedical and public health interventions in Uganda. Athens: Ohio University Press. 2017.

TAYLOR-ROBINSON, David C. et al. Deworming drugs for soil-transmitted intestinal worms in children: effects on nutritional indicators, haemoglobin and school 
performance. Cochrane Database Systematic Reviews, v.11, n.7, p.1-157. 2015.

TSONGO, Esdras; RATCLIFFE, Rebecca. Rumor and violence rife as Ebola outbreak surges out of control. The Guardian, 26 Apr. 2019.

US CDC.

US Centers for Disease Control. Parasites: ascariasis. Available at: <http://www.cdc.gov/ parasites/ascariasis $>$. Access on: 25 Apr. 2019. 15 Feb. 2018.

\section{US CDC.}

US Centers for Disease Control. Parasites: hookworm. Available at: <http://www.cdc.gov/ parasites/hookworm>. Access on: 25 Apr. 2019. 10 Jan. 2013a.

US CDC.

US Centers for Disease Control. Parasites: trichuriasis. Available at: <http://www.cdc.gov/ parasites/whipworm>. Access on: 25 Apr. 2019. 10 Jan. 2013b.

WAMMES, Linda J. et al.

Helminth therapy or elimination:

epidemiological, immunological, and clinical considerations. Lancet Infectious Diseases, v.14, n.11, p.1150-1167. 2014.
WEBB JR., James L.A.

The guts of the matter: a global history of human waste and infectious intestinal disease. New York: Cambridge University Press. 2020.

WEBB JR., James L.A.

Aedes aegypti suppression in the Americas: historical perspectives. Lancet, v.388, n.10044, p.556-557. 2016.

WEBB JR., James L.A.

The long struggle against malaria in tropical Africa. New York: Cambridge University Press. 2014.

WEBB JR., James L.A.

The first use of synthetic insecticides for malaria control in tropical Africa: lessons from Liberia 1945-1962. Journal of the History of Medicine and Allied Sciences, v.66, n.3, p.347-376. 2011.

WEBB JR., James L.A.

Humanity's burden: a global history of malaria. New York: Cambridge University Press. 2009.

WHO.

World Health Organization. Fact sheet: Ebola virus disease. Available at: <http://www.who. int/en/news-room/fact-sheets/detail/ebolavirus-disease $>$. Access on: 10 May 2019. n.d.

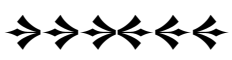

